\title{
James A. Nicholas
}

Faleceu em Nova York, onde vivia e trabalhava, o Professor James Nicholas, um dos ícones mundiais da Ortopedia e um dos maiores nomes da Cirurgia do Joelho e da Medicina Esportiva.

No Lenox Hill Hospital de Nova York era Diretor do Departamento de Ortopedia e do Instituto de Medicina Esportiva e Trauma. Professor de Clínica Ortopédica da New York University e do New York Medical College, foi autor de inúmeros trabalhos e publicou duas Enciclopédias Médicas: "The Lower Extremity and the Upper Extremity and Spine in Sports Medicine", com mais de 2.000 páginas.

O Professor Nicholas sempre recebeu em seu Serviço, em Nova York, vários ortopedistas brasileiros, aos quais dispensava atenção e carinho especiais.

Possuidor de um carisma extraordinário, revolucionou o mundo com seus conceitos em Cirurgia do Joelho, na década de 70 .

Adorava o Brasil, onde veio, como convidado especial, para Congressos. Sempre se destacou na Ortope- dia mundial, sendo considerado um dos líderes inesquecíveis em sua especialidade.

A Ortopedia perde um de seus grandes expoentes, que eternamente será lembrado por sua inteligência, elegância e, principalmente, por seu profundo conhecimento e sábios ensinamentos.

Os que o conheceram na

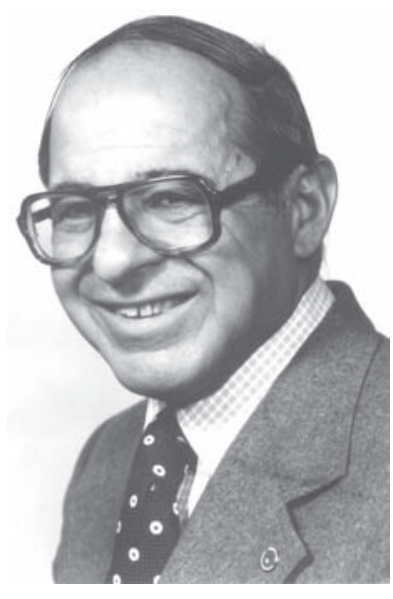
sua vida profissional e intimidade familiar se sentem órfãos e saudosos de um grande mestre e amigo.

\section{NeYLOR PACE LASMAR}

Professor Titular de Ortopedia e Traumatologia da Faculdade de Ciências Médicas de Minas Gerais Presidente da SBOT - Gestão 2004/2005 